\title{
Imagens, ruínas e mundo por vir: deslocamento por lugares e corpos tikmũu, ũn
}

Images, ruins and becoming world: displacement across tikmũ,ũn places and bodies

\section{Douglas Ferreira Gadelha Campelo}

\section{(2) OpenEdition}

\section{Edição electrónica}

URL: http://journals.openedition.org/aa/5902

DOI: $10.4000 /$ aa. 5902

ISSN: 2357-738X

\section{Editora}

Programa de Pós-Graduação em Antropologia Social (UnB)

Edição impressa

Paginação: 239-256

ISSN: 0102-4302

\section{Refêrencia eletrónica}

Douglas Ferreira Gadelha Campelo, «lmagens, ruínas e mundo por vir: deslocamento por lugares e corpos tikmũ,ũn», Anuário Antropológico [Online], v.45 n.2 | 2020, posto online no dia 29 maio 2020, consultado o 27 abril 2021. URL: http://journals.openedition.org/aa/5902 ; DOI: https://doi.org/ 10.4000/aa.5902

\section{(c) (i) (9)}

Anuário Antropológico is licensed under a Creative Commons Atribuição-Uso Não-Comercial-Proibição de realização de Obras Derivadas 4.0 International. 


\section{Imagens, ruínas e mundo por vir: deslocamento por lugares e corpos tikmũ,ũn}

Images, ruins and becoming world:

displacement across tikmũ,ũn places and bodies

DOI: https://doi.org/10.4000/aa.5902

Douglas Ferreira Gadelha Campelo • Universidade Federal de Santa Catarina - Brasil

Pós-doutorando no Programa de Pós-graduação em Antropologia Social, Universidade Federal de Santa

ORCID: $9000-0002-9836-7331$

Catarina. Bolsista CAPES/PNPD.

Neste ensaio fotográfico procuro percorrer, em conjunto com caçadores tikmũ,ũn, imagens que anunciam historicidades através dos corpos e dos lugares fotografados. As imagens buscam adentrar no emaranhado de capim e em pequenos cursos de água onde pessoas tikmũ,ũn, comumente chamadas pelo etnônimo Maxakali, seguem com as linhas das suas vidas no nordeste mineiro, quase na fronteira com o sul da Bahia. Fotografia. Etnografia. Territorialidade. Etnohistória. Tikmũ,ũn.
In this photographic essay, along with tikmũ,ũn hunters, I intend to go through images which announce various historicities by means of the photographed bodies and places. Those images pervade the tangled grass and short watercourses where tikmũ,unn people lead their lives in the northeast part of Minas Gerais, close to southern Bahia state border. In the past, farms were built, and colonião-grass were grown there, in tikmũ,ũn territory. 
As fotos escolhidas para compor este ensaio ${ }^{1}$ fotográfico foram capturadas próximo ao término de um trabalho de campo que realizei ao longo de 14 meses, entre os anos de 2014 e 2016, em diferentes aldeias tikmũ, ũn, nas zonas limítrofes entre o sul da Bahia e o nordeste de Minas Gerais². Atualmente, pessoas tikmũ,ũn - mais conhecidas pelo etnônimo Maxakali - somam algo em torno de 2.200 pessoas. As aldeias tikmũ,ũn localizadas na Terra Indígena Maxakali situam-se em duas localidades, Água Boa e Pradinho. Elas estão vinculadas, respectivamente, aos municípios de Santa Helena de Minas e Bertópolis, no estado de Minas Gerais. Além da Terra Indígena, após um intenso conflito envolvendo praticamente toda a população tikmũ,ũn entre os anos de 2004 e 2005, uma parcela da população tikmũ,ũn vive atualmente em duas reservas indígenas, Aldeia Verde e Aldeia Cachoeirinha, situadas nas proximidades do município de Teófilo Otoni.

Como tantos outros, esses indígenas vivem em um regime de confinamento territorial. Habitando em uma terra totalmente devastada e estilhaçada, que não lhes garante sua soberania alimentar, vivem uma situação de profunda dependência de recursos governamentais. Apesar disso, o que pretendo demonstrar neste ensaio fotográfico é que, embora as forças coloniais tentassem impor a eles um confinamento territorial, isso nunca os impediu de viver um outro território existencial ${ }^{3}$.

De certa forma, as fotos apresentadas aqui foram as poucas que me atrevi a fazer. Minha câmera, uma Fuji FinePix S4080, na maior parte do tempo, circulava nas mãos dos adolescentes da aldeia, que faziam fotos e as apagavam de maneira quase compulsiva. Creio que as fotos deste ensaio se aproximam dos períodos em que senti maior imersão em campo, nos quais os temas e as questões da pesquisa se aproximavam de um delineamento mais definido. Aos poucos percebia que meu interesse se aproximava das estórias que emanavam dos lugares habitados por pessoas tikmũ,ũn ${ }^{4}$. Assim, vivendo em uma terra tomada por capim-colonião, me perguntava quais as estórias podiam emanar dali. O que os entrelaçamentos da malha composta por pessoas tikmũ,ũn, fazendeiros, comerciantes, capim, vacas, bois e espíritos teriam a nos revelar sobre esse contexto etnográfico?

As imagens que se seguem tentam adentrar na densidade dessa malha entrelaçada à beira do córrego Umburanas. Ali, os corpos tikmũ,ũn se deslocam em meio a uma terra "branquificada", como nos lembra Tomé Maxakali, transformada ao longo do século XX em pasto e fazenda ${ }^{5}$. Uma terra que anteriormente era uma densa, complexa e rica mata Atlântica transformou-se em um tedioso deserto verde formado de capim-colônia e algumas poucas áreas de mata. Esse processo de "branquificação" da terra foi amplamente incentivado pelos arrendamentos de terra, promovidos pelo Serviço de Proteção aos Índios (SPI) e Fundação Nacional do Índio (Funai), ao longo do século XX, em conluio com fazendeiros e políticos locais ${ }^{6}$.

Nessa terra, pessoas tikmũ,ũn construíram - e constroem - seus corpos resistindo como podem. As caçadas às capivaras são frequentemente realizadas por caçadores tikmũ,ũn como forma de fazer oferendas sacrificiais aos yãmĩyxop (coletivo de povos-espírito), que vêm até as aldeias cantar, dançar, caçar, brincar, banquetear, fazer sexo, casar e curar. No passado, enquanto suas terras eram tomadas por fazendeiros, os caçadores tikmũ,ũn, em conjunto com os yãmĩyxop, caçavam
1 Este ensaio é o resultado de uma pesquisa de doutorado concluída (Cf. Campelo, 2018) e de um estágio de pós-doutorado em andamento. Agradeço à CAPES pela bolsa ao longo do doutorado e à bolsa que recebi para estágio de pós-doutorado. Agradeço ainda os(as) pareceristas, cujas sugestões procurei incorporar o máximo que pude neste ensaio.

2 Cf. Campelo (2018).

3 Sobre a noção de território existencial, ver Glowckzewski (2008; 2015) e Guatari (2012).

4 Tenho optado utilizar a expressão pessoas tikmũ,ũn, ou simplesmente tikmũ,ũn, ao invés do etnônimo Maxakali ou do binômio tikmũ,ũn/ maxakali. Utilizo tikmũ,ũn como um conceito, uma noção de pessoa que está em constante elaboração por parte de seus agentes. Discuto de maneira mais detalhada essa escolha em Campelo (2018).

5 Para o conceito de embranquecimento das terras tikmũ,ũn, cf. Berbert e Campelo (2018).

6 Cf. Rubinger (1980) e Berbert e Campelo (2018). 
as vacas, que eram distribuídas ritualmente nas aldeias. Através da circulação da carne de caça, bem como da circulação dos cantos dos yãmĩyxop, é que se faz e se constrói a pessoa e o corpo tikmũ,ũn. A pessoa tikmũ,ũn deve, ao longo da sua vida, fazer circular em seu corpo e nos dos demais os cantos dos yãmĩyxop ${ }^{7}$. Por isso, é importantíssimo o engajamento quando os yãmĩyxop estão presentes nas aldeias. As fotos abaixo adentram um pouco nesse universo.

Sob tal ângulo, este ensaio fotográfico se aproxima de duas perspectivas. $\mathrm{Na}$ primeira parte do ensaio, procuro adentrar nos emaranhados de capim, rios, fazendas por meio de cenas de caça a capivara ${ }^{8}$. Quando vemos as ruínas das fazendas e do antigo Posto Indígena Mariano de Oliveira, bem como o mar de capim, nos aproximamos de testemunhas materiais de uma historicidade que emana daquele lugar. Estas sequências de fotos aconteceram em momentos de muita saturação de luz. Diante de tais condições, me pareceu mais simples realizá-las em preto e branco. No entanto, as fotos em preto e branco funcionam neste ensaio como uma performance para dar contorno a esse território morto, que passa por um "embranquecimento". Ao mesmo tempo, contudo, mesmo diante desse cenário distópico, pessoas tikmũ,ũn tentam produzir um devir tikmũ,ũn nestes lugares 9 .

A segunda parte do ensaio trata dos momentos posteriores à circulação da carne de caça no interior das relações tikmũ,ũn. As fotos se aproximam do momento em que ocorre a festa do coletivo de espíritos-anta (ãmãxuxop), que trazem danças e cantos do ponto de vista de antas, veados, capivaras e vacas. Estes conjuntos de espíritos dançam com as mulheres tikmũ,ũn. Elas, por sua vez, ensaiam formas de armadilha-captura destes seres, transmutando olhares e perspectivas ${ }^{10}$. Geralmente, estes períodos ocorrem ao final da tarde ou no início da manhã, o que me facilitou - e muito - fazer fotos coloridas. Há neste ensaio, portanto, uma sobreposição ontológica de um mundo morto, em ruínas - fruto da colonização das terras tikmũ,ũn pelos brancos - e, de outro lado, um mundo por vir - fruto da agência tikmũ,ũn na sua terra. Esse mundo por vir é um mundo depois da morte. Um mundo que devir yãmĩyxop.
7 Sobre a relação entre a noção de corpo e a circulação de cantos na pessoa tikmũ,ũn, ver Álvares (1992) e Campelo (2018).

8 Convido o leitor a assistir ao filme Caçando capivara, do realizador Marilton Maxakali.

9 O termo devir tikmũ,ũn foi cunhado por Romero (2015) em sua dissertação de mestrado.

10 Para uma análise da interação entre yãmĩyxop e mulheres tikmũ,ũn, cf. Campelo (2009; 2015) e Pires Rosse (2007). 


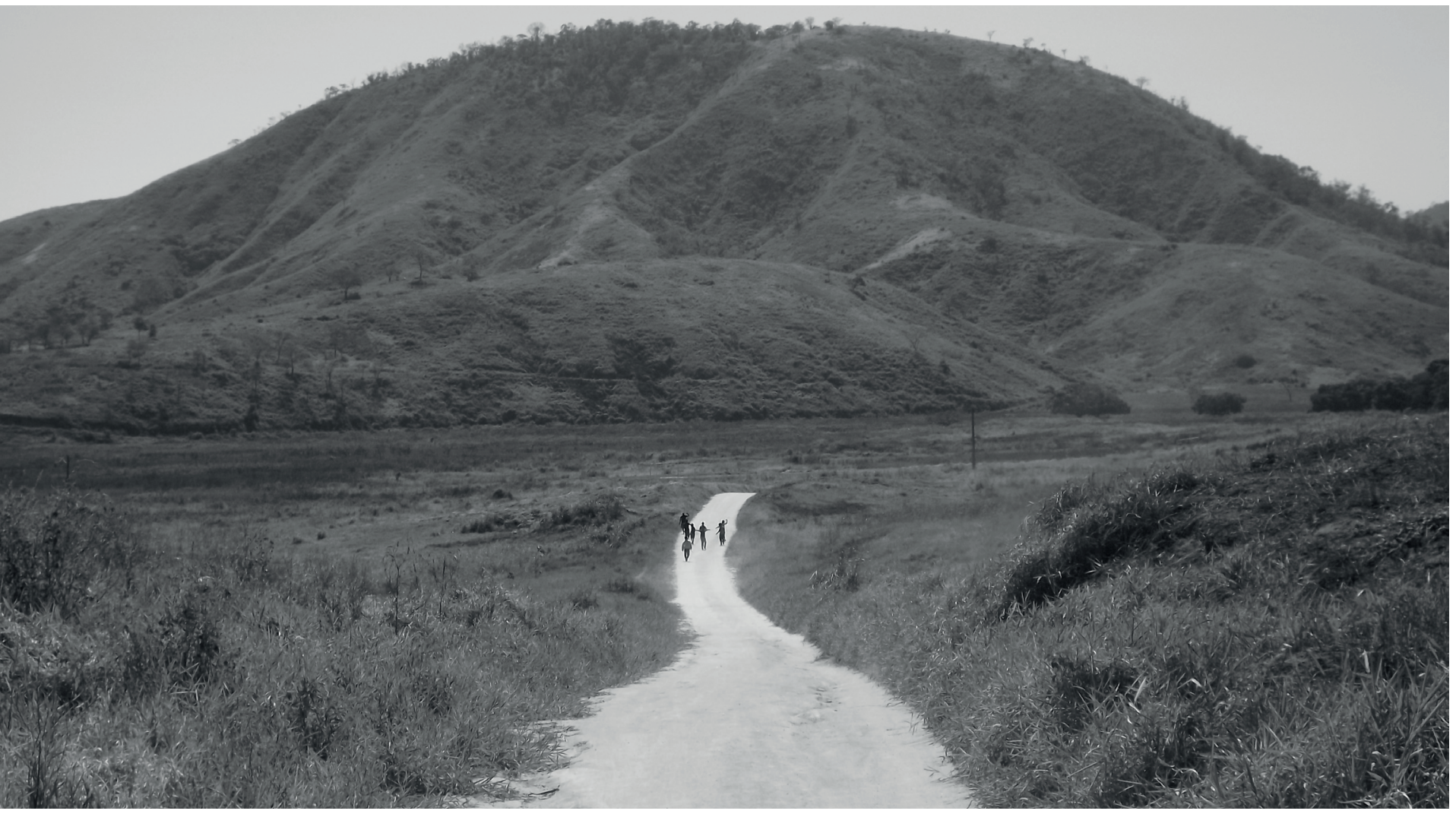

Deslocamento de caçadores até as proximidades do córrego Umburanas para a

caça de capivaras - Terra Indígena Maxakali, Pradinho, setembro de 2015 
Douglas Ferreira Gadelha Campelo
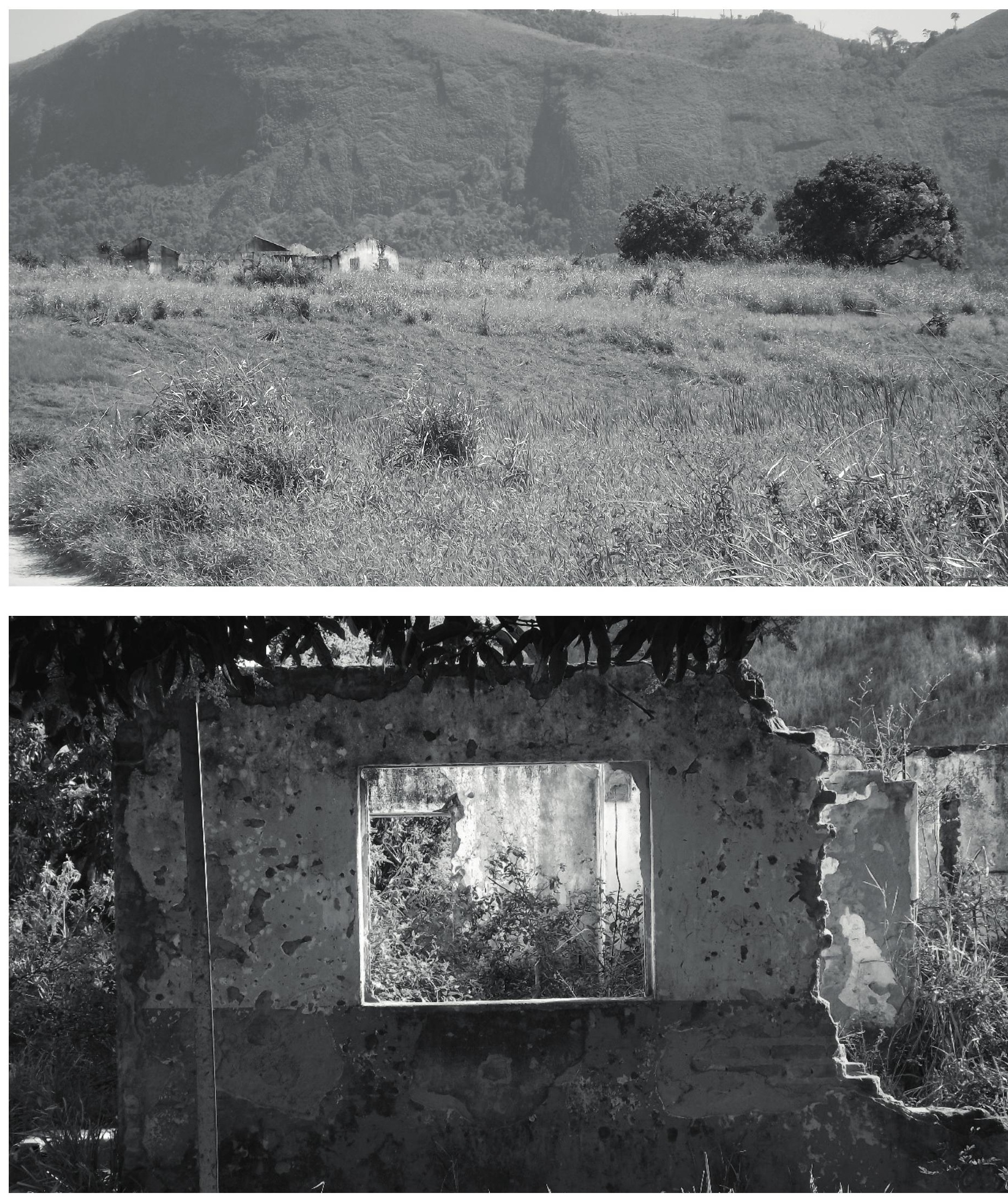

Antiga fazenda no interior da Terra Indígena Maxakali (Pradinho, setembro de 2015) e ruínas do Posto Indígena Mariano de Oliveira na Terra Indígena Maxakali (Água Boa, setembro de 2014) 
Douglas Ferreira Gadelha Campelo

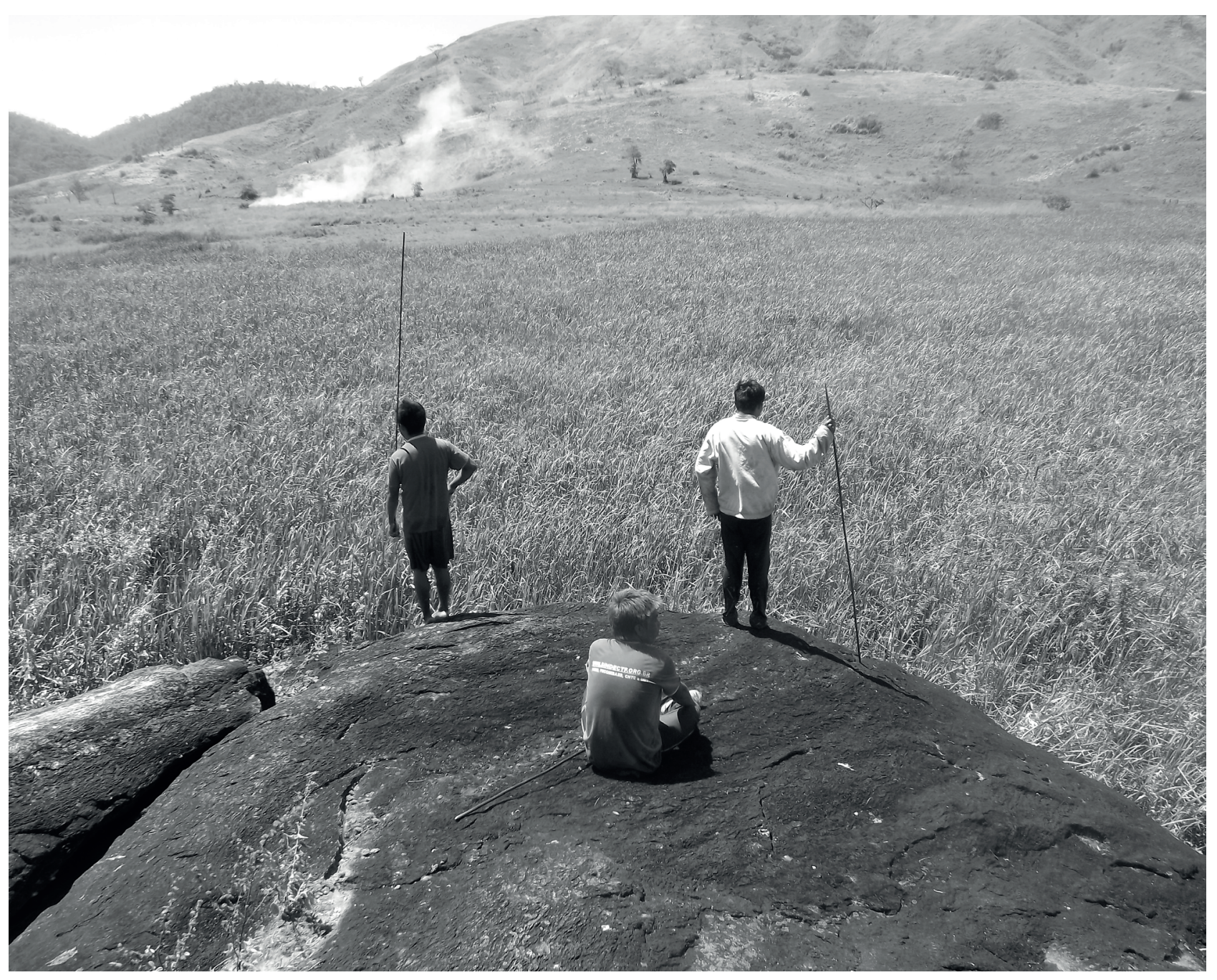

Caçadores tikmũ,ũn observando capivaras - Terra Indígena

Maxakali, Pradinho, setembro de 2015 
Douglas Ferreira Gadelha Campelo

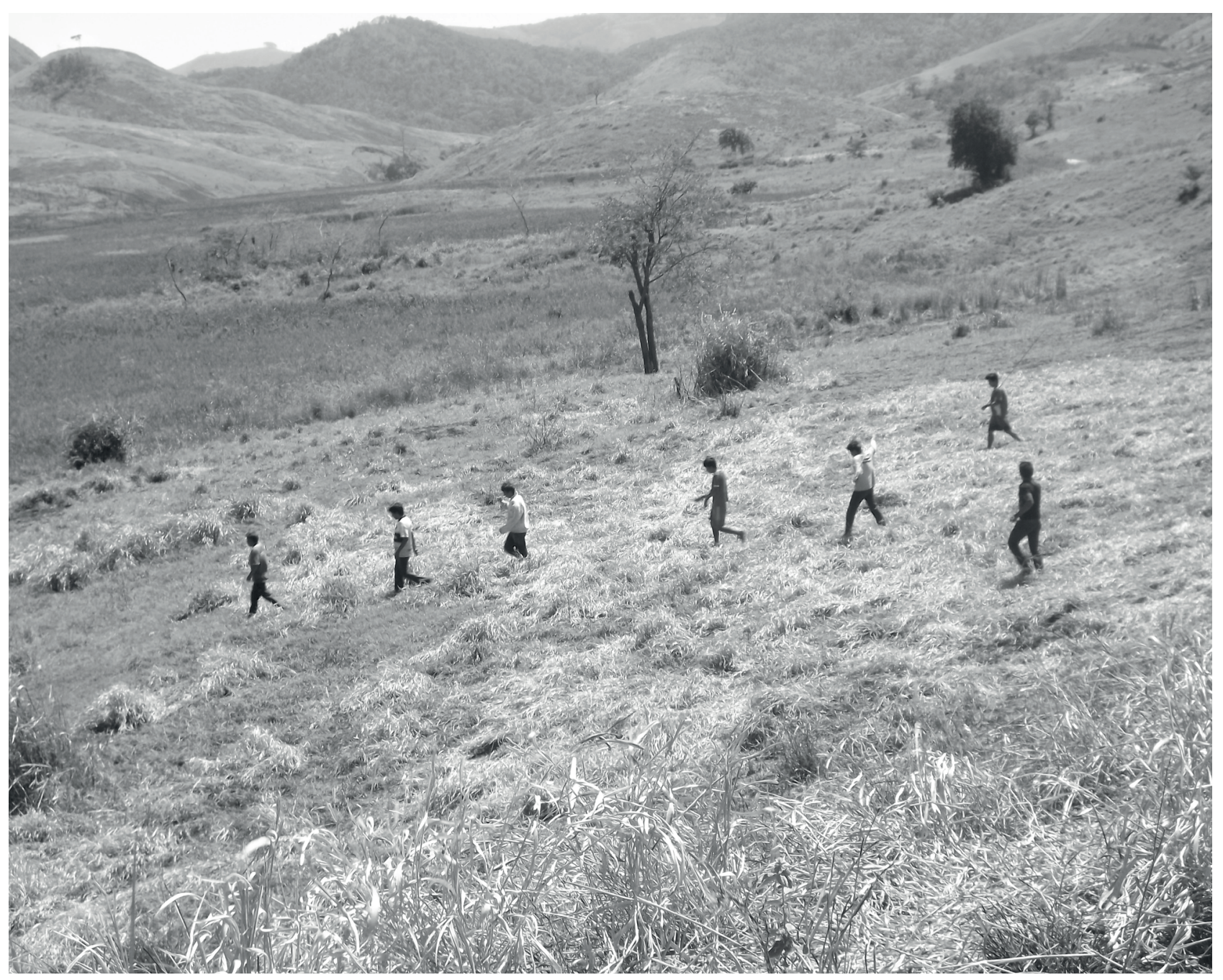

Atrás dos rastros de capivaras - Terra Indígena Maxakali,

Pradinho, setembro de 2015 


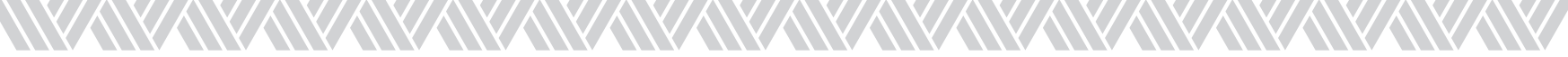

Imagens, ruínas e mundo por vir

ENSAIO VISUAL

Douglas Ferreira Gadelha Campelo

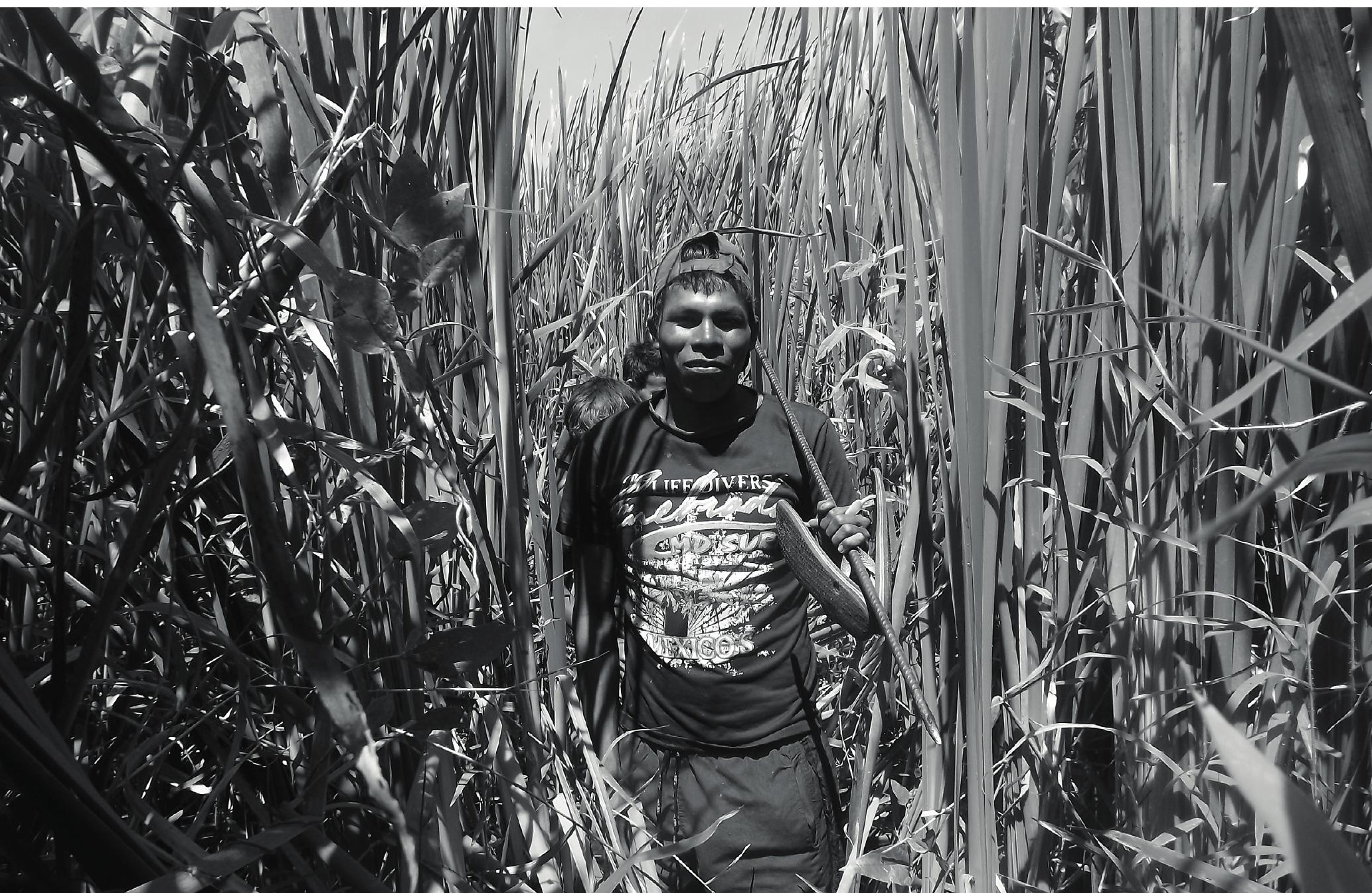

Caçador Maxakali no interior de matagal, nas proximidades do córrego

Umburanas -Terra Indígena Maxakali, Pradinho, setembro de 2015 


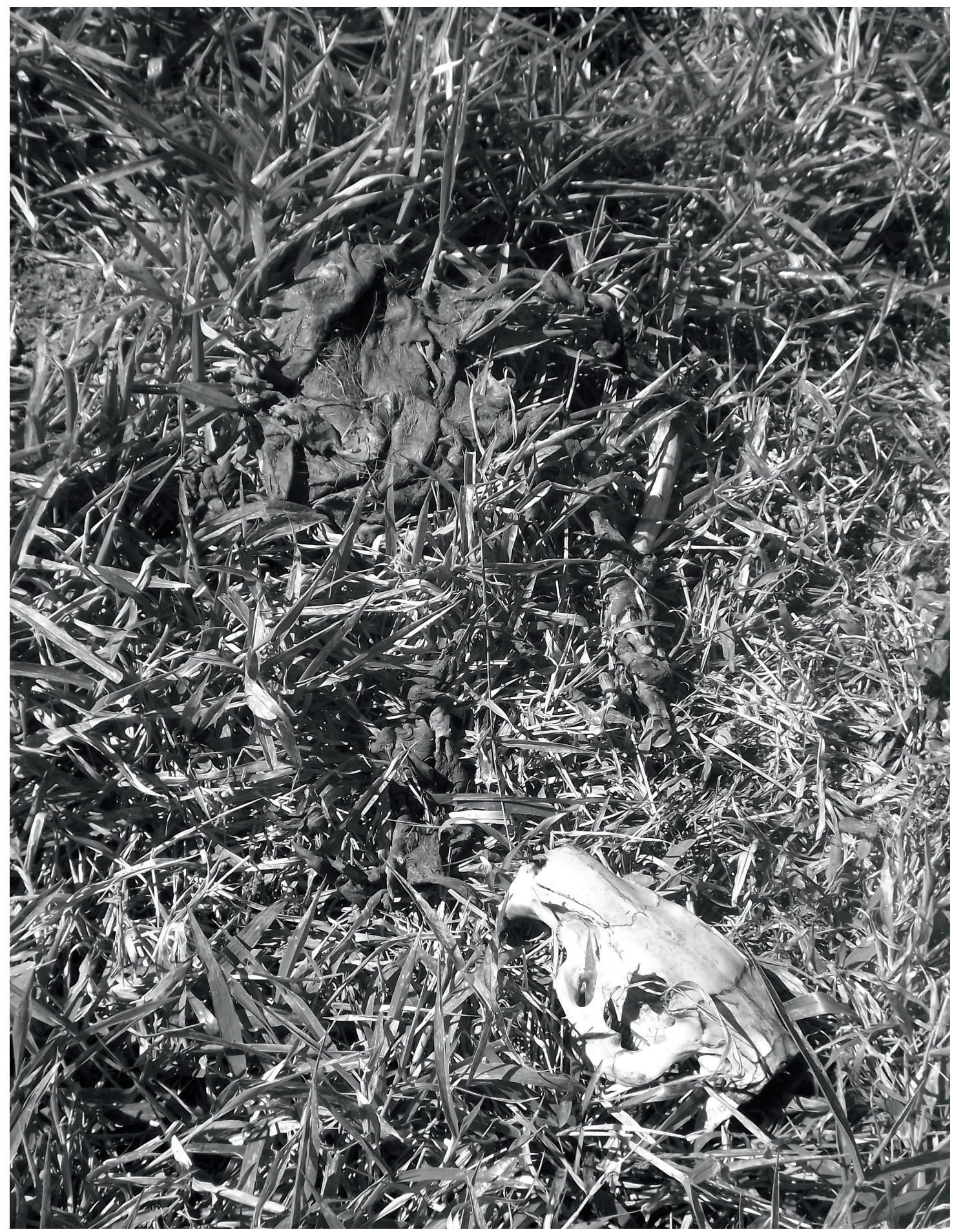

Crânio e couro de capivara -Terra Indígena Maxakali, Pradinho, setembro de 2015 
Douglas Ferreira Gadelha Campelo

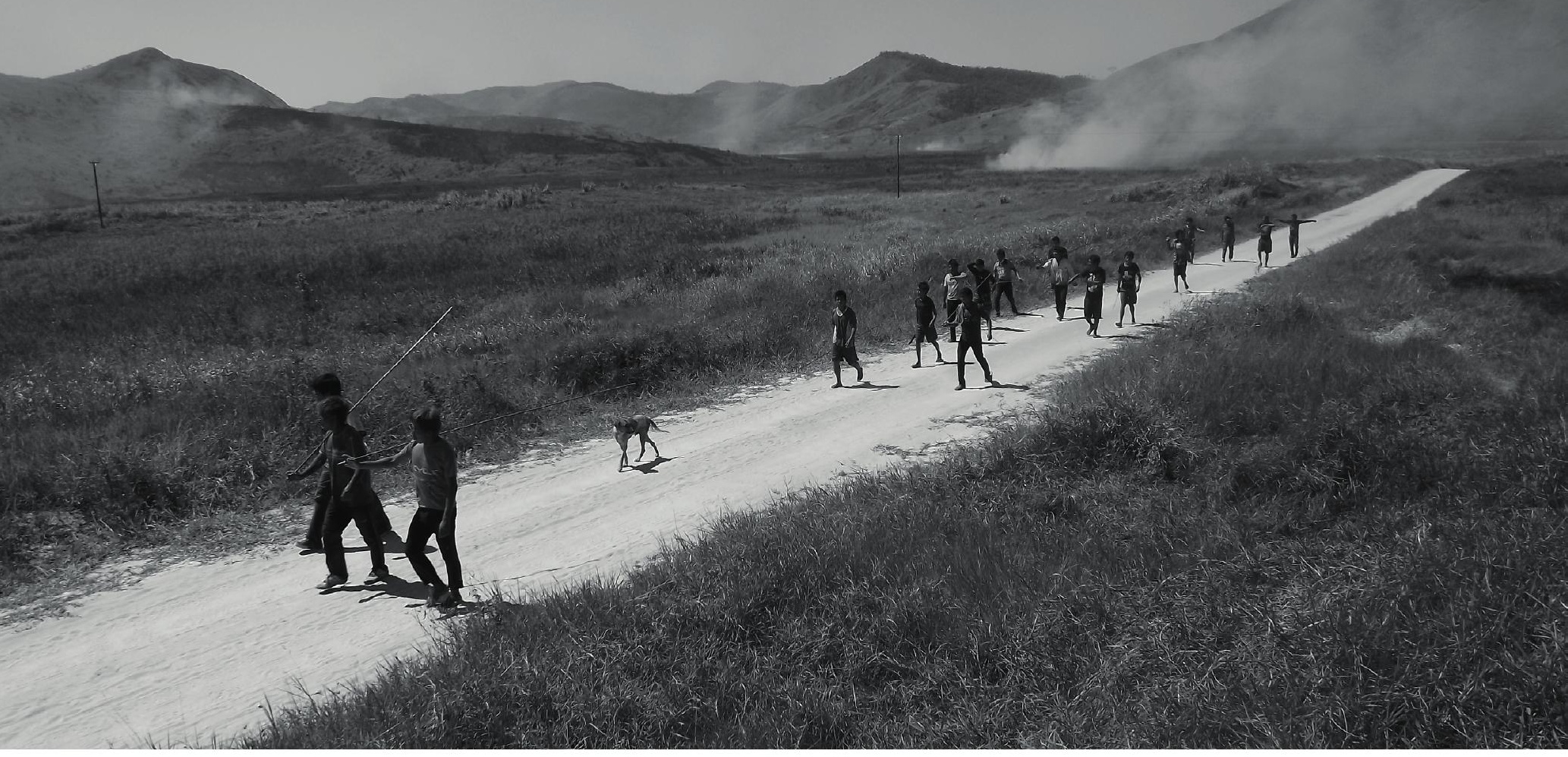

Caçadores tikmũ,ũn retornam para suas casas - Terra Indígena

Maxakali, Pradinho, setembro de 2015 


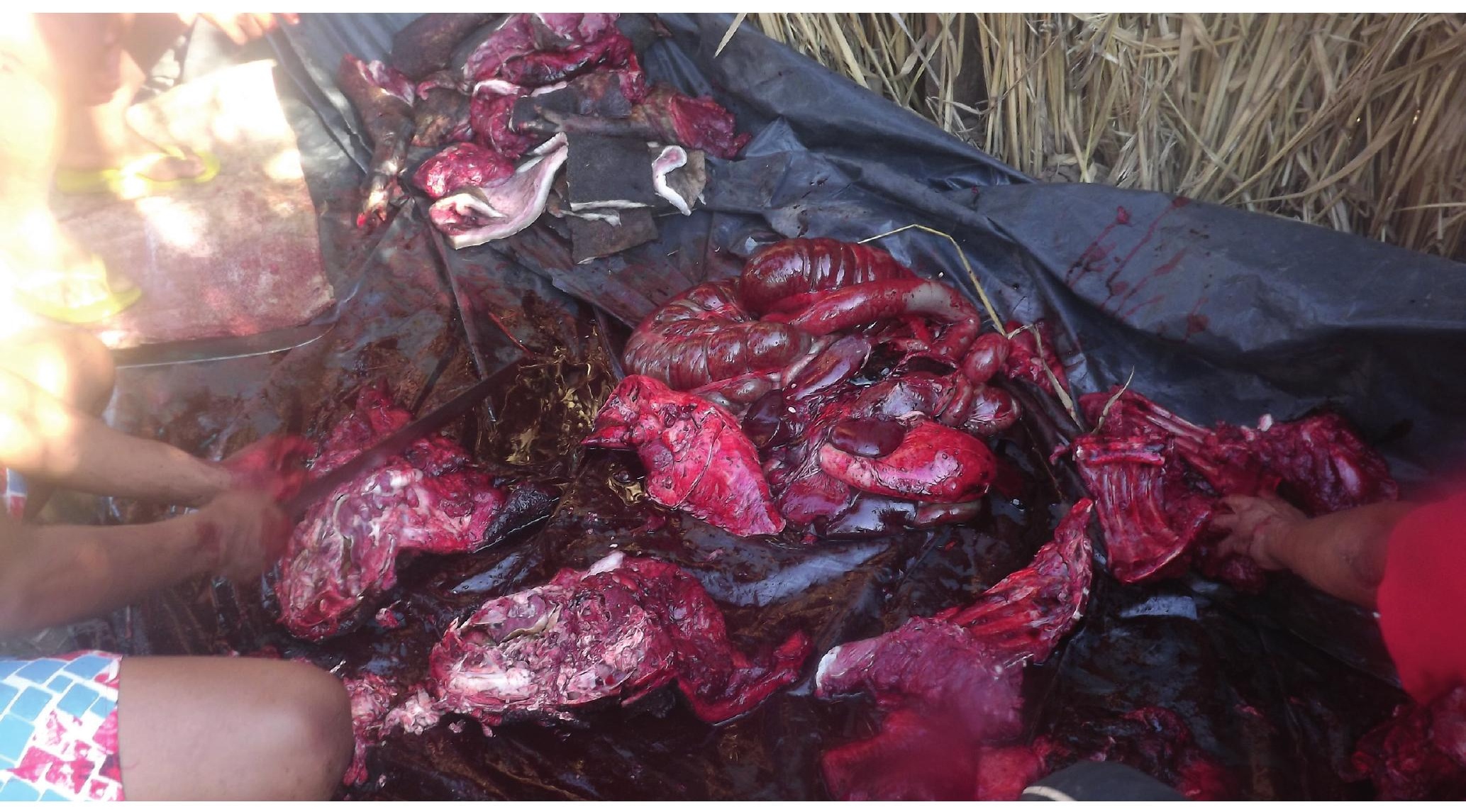

Partilha da carne de caça a ser distribuída na festa das antas (ãmãxuxop) na aldeia Novila - Terra Indígena Maxakali, Pradinho, setembro de 2015 


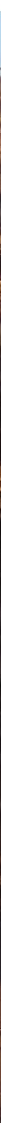

Ãmãxux dançando no pátio da aldeia Novila - Terra Indígena

Maxakali, Pradinho, setembro de 2015 
Douglas Ferreira Gadelha Campelo

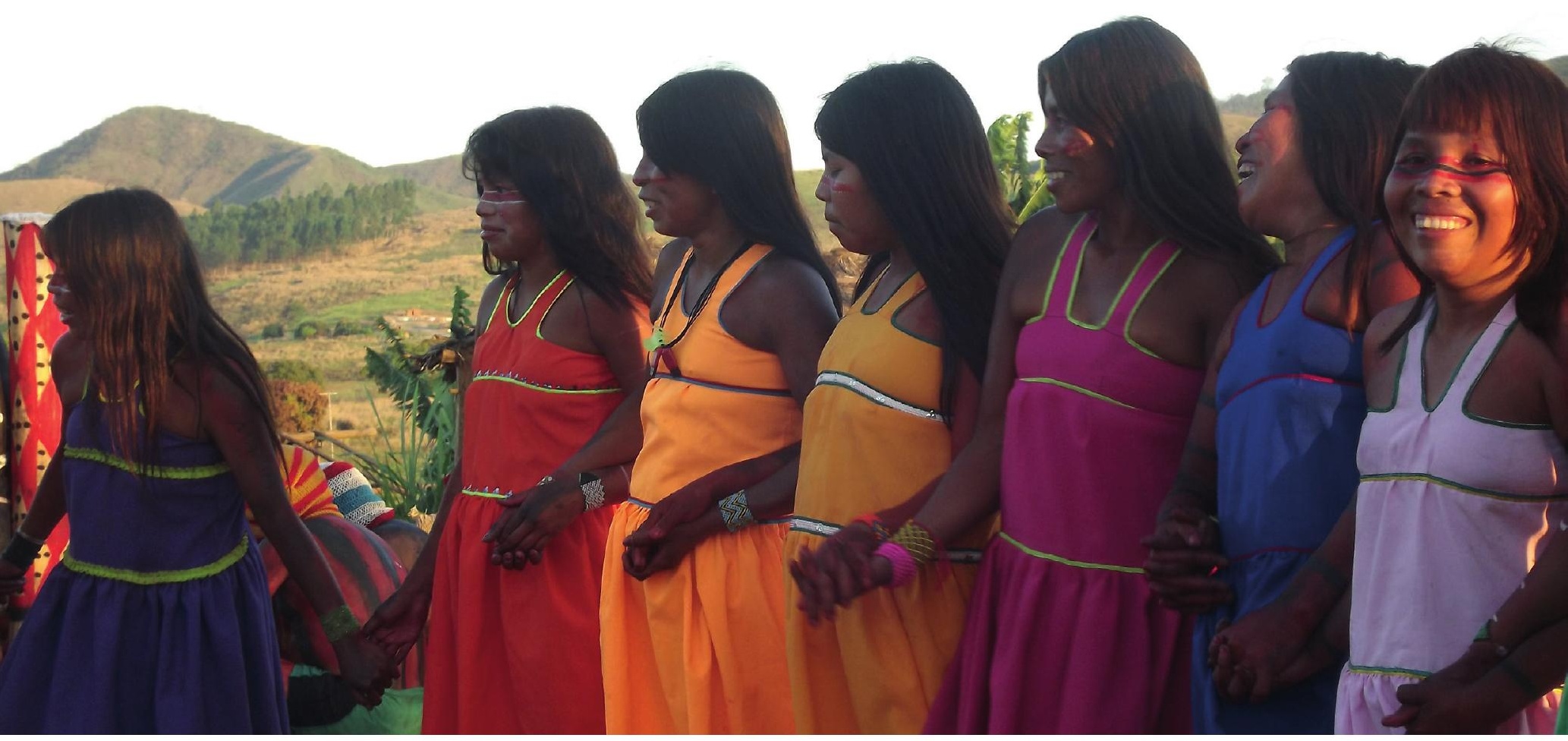

Aproximação feminina das ãmãxuxxop na aldeia Novila - Terra

Indígena Maxakali, Pradinho, setembro de 2015 


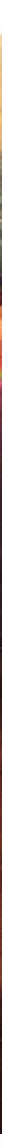

Observação feminina do deslocamento das ãmãxuxop na aldeia

Novila - Terra Indígena Maxakali, Pradinho, setembro de 2015 
Douglas Ferreira Gadelha Campelo

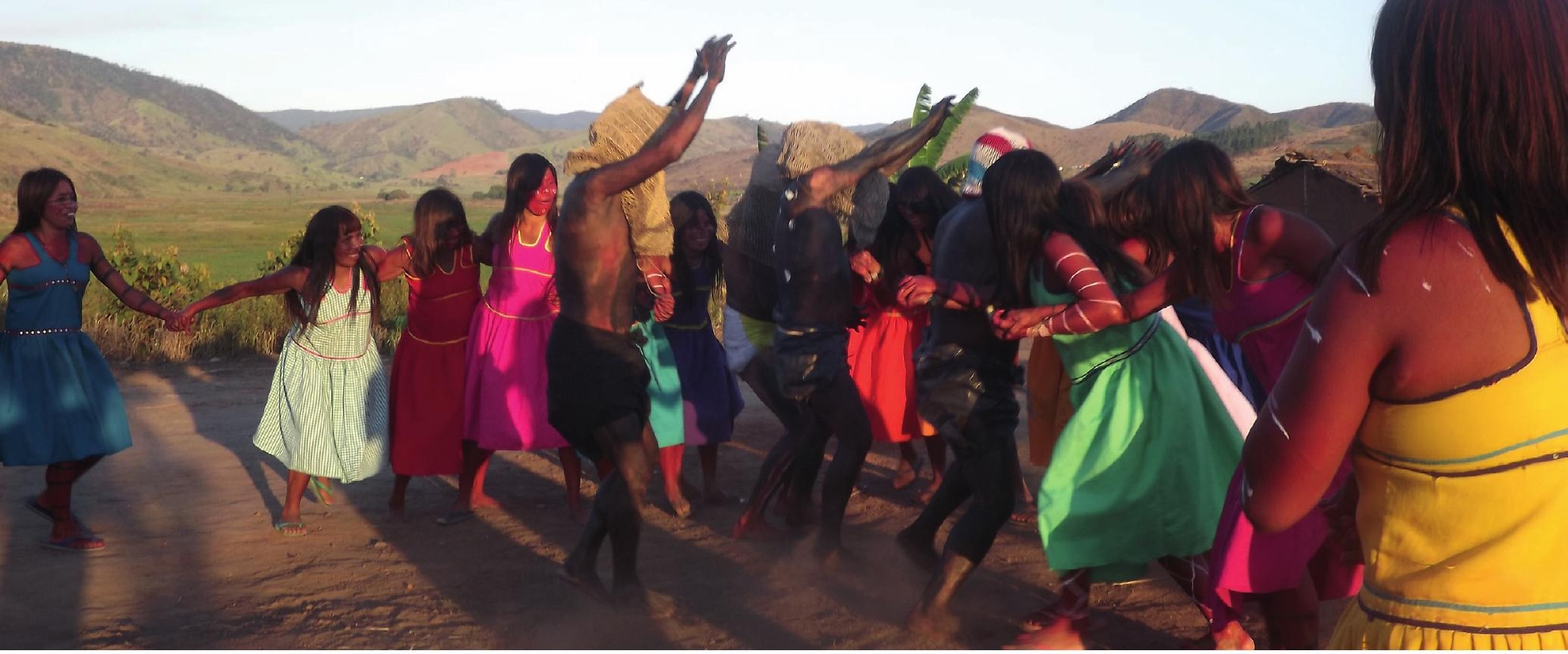

Dança-captura das ãmãxuxxop na aldeia Novila - Terra Indígena

Maxakali, Pradinho, setembro de 2015 
Douglas Ferreira Gadelha Campelo

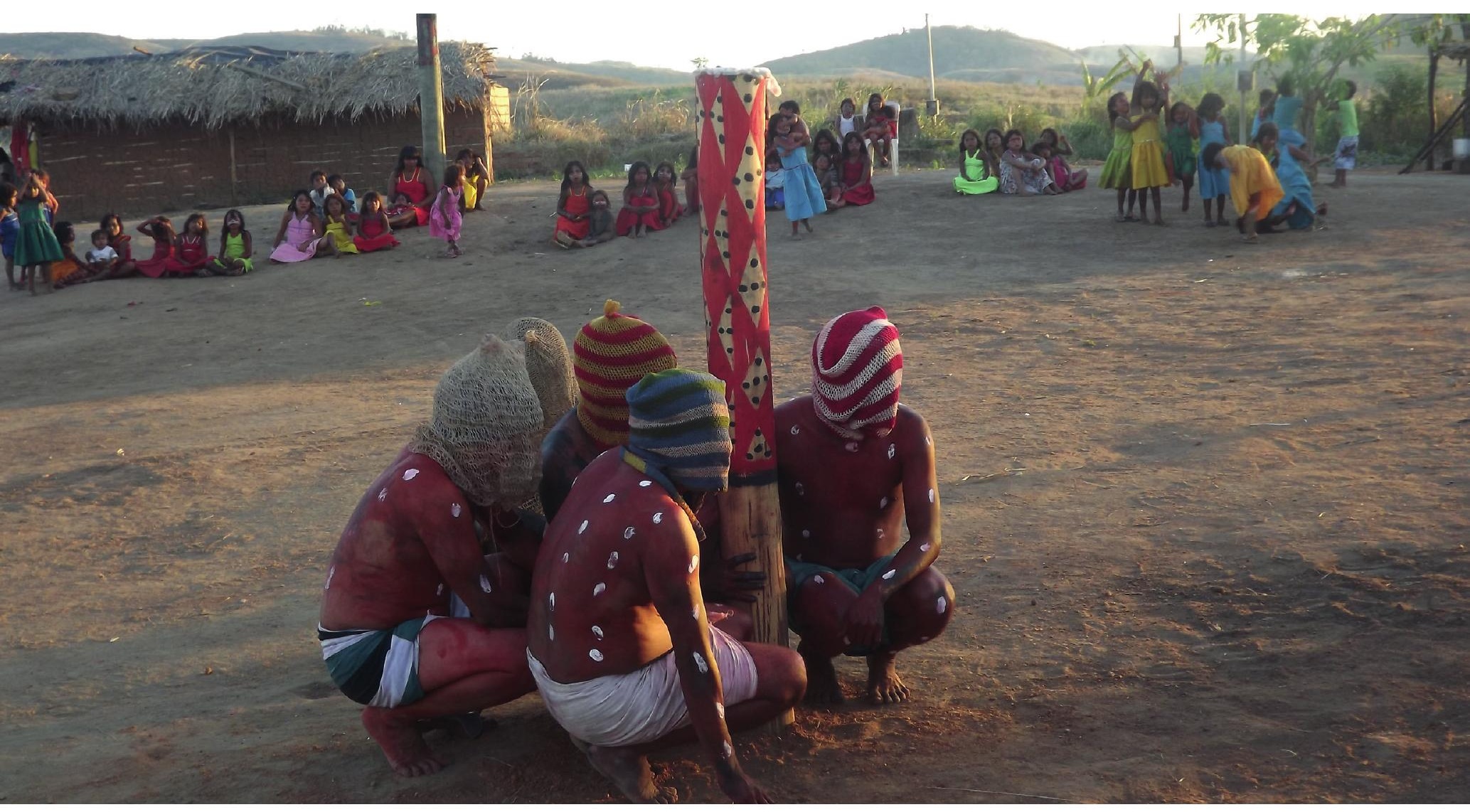

Ãmãxuxxop - coletivo-anta - Terra Indígena

Maxakali, Pradinho, setembro de 2015 


\section{Referências}

ÁLVARES, Myriam Martins. Yãmiy, os espíritos do canto: a construção da pessoa na sociedade maxakali. Dissertação (Mestrado em Antropologia Social) - Instituto de Filosofia e Ciências Humanas, Universidade Federal de Campinas, Campinas, 1992.

BERBERT, Paula; CAMPELO, Douglas Ferreira Gadelha Campelo. Embranquecer as terras, disciplinar os corpos: notas sobre a política indigenista junto aos Tikmũ,ũn_Maxakali entre 1940 e 1988. Espaço Ameríndio, v. 12, n. 2, p. 129-179, 2018.

CAMPELO, Douglas Ferreira Gadelha. Ritual e Cosmologia Maxakali: uma etnografia da relação entre os espíritos-gaviões e os humanos. Dissertação (Mestrado em Antropologia Social) - Faculdade de Filosofia e Ciências Humanas, Universidade Federal de Minas Gerais, Belo Horizonte, 2009.

CAMPELO, Douglas Ferreira Gadelha. En torno a una estética perspectivista de la predación: ensayo etnográfico sobre la relación entre los pueblos tikmu,un/maxakali y los espiritos águilas. In: BRABEC DE MORI, Bernd; GARCIA, Miguel A.; LEWY, Matthias (Eds.). Sudamérica y sus mundos audibles: cosmologias y prácticas sonoras de los pueblos indígenas. v. 1. 8. ed. Berlin: Gebr. Mann Verlag, 2015. p. 1-272.

CAMPELO, Douglas Ferreira Gadelha. Das partes da mulher de barro: a circulação de povos, cantos e lugares na pessoa tikmũ,ũn. Tese (Doutorado em Antropologia Social) - Centro de Filosofia e Ciências Humanas, Universidade Federal de Santa Catarina, Florianópolis, 2018.

GLOWCZEWSKI, Bárbara. Guatari et l'Anthropologie: aborigènes et territoires existentiel. Multitudes, v. 3, n. 34, p. 84-94, 2008.

GLOWCZEWSKI, Bárbara. Devires totêmicos: cosmopolítica do sonho. São Paulo: N-1, 2015.

GUATTARI, Félix. Caosmose: um novo paradigma estético. São Paulo: Editora 34, 2012.

PIRES ROSSE, Eduardo. A explosão de Xunim. Dissertação (Mestrado em Etnomusicologia) - Universidade PARIS 8, Paris, 2007.

ROMERO, Roberto. A Errática tikmũ'ũn_maxakali: imagens da Guerra contra o Estado. Dissertação (Mestrado em Antropologia) - Programa de Pós-graduação em Antropologia Social do Museu Nacional, Rio de Janeiro, 2015.

RUBINGER, Marcos Magalhães. Situação atual no Médio Jequitinhonha. In:RUBINGER, Marcos Magalhães; AMORIM, Maria Stella de; MARCATO, Maria Stella de (Ed.). Índios Maxakali: resistência ou morte. Belo Horizonte: Interlivros, 1980. p. 9-124. 